\title{
Numerical Investigation of Air Flow and Temperature Distribution in a Trombe Wall System: A CFD Study
}

\author{
Bharath $V^{\# 1}$, Puneeth Kumar M V ${ }^{\# 2}$, Preetham B M ${ }^{\# 3}$, Shashikanth ${ }^{* 4}$ \\ \# 1-3 Department of Mechanical Engineering, \\ Sri Venkateshwara College of Engineering, Bengaluru, Karnataka, India \\ 1vbharath1947@gmail.com \\ 2puni053@gmail.com \\ 3preeth.bm@gmail.com \\ ${ }^{* 4}$ Department of Mechanical Engineering, \\ Mallareddy Engineering College, Secunderabad, Telangana, India \\ shashimech092@gmail.com
}

\begin{abstract}
The utilization of fossil fuels in the day to day life has a huge impact on the environment because of which the renewable energy resources have become a mandatory choice of interest. The solar energy in particular plays a critical role in reducing the annual energy demand in the building industry especially in schools, hospitals and underdeveloped areas. In the present work a detailed study on the Trombe wall system which is an architectural arrangement that is used for either passive heating or cooling inside the building has been made. The scope of work involves the modelling, meshing and analysis of a particular Trombe wall system used for passive cooling. The flow and the temperature fields are simulated in 2D. Parametric study has been conducted for various external inlet air temperature. The Gambit 2.3.16 software has been utilized to obtain complete modelling and meshing while Ansys Fluent 6.3.26 CFD code solver has been used for analysis. The current study could be beneficial to progress the utilization of solar energy in the building industry effectively.
\end{abstract}

Keyword - Renewable Energy, Trombe Wall, Passive Cooling, Computational Fluid Dynamics

\section{INTRODUCTION}

The impact on the environment and the rapid growth in the price are the important factors concerned with the utilization of fossil energy which is an essential component of daily life. As a result the renewable sources of energy such as sun, wind, biomass, waves, rain, tides and geo thermal heat has gained lot of importance. Solar energy in particular has got wide spread usage as it can be used in almost all parts of the world including the remote and underdeveloped regions. It can be used for space heating which can reduce the annual heating demand to nearly about $25 \%$ in the building sector [1].Hence the solar space heating plays a critical role in the minimal usage of the non-renewable energy sources. The space heating can be done utilizing both the active and passive solar techniques. The active is one in which a mechanical device like a fan or a blower is used where as in the later one it is not used. Therefore it is essential to study the Passive solar techniques which are not only energy saving but also economical. The present work includes the utilization of CFD [2] - [3] to simulate a particular Trombe wall system for summer cooling considering both conduction and convection modes of heat transfer. Parametric studies has been carried out in order to determine the influence of inlet air temperature on the system and also the position of the vent in the exterior wall side.

\section{LITERATURE SURVEY}

S J Ormiston et. al. [4] carried out numerical predictions of heat transfer in a Trombe wall system and also have fully taken into account the interaction between the room and the channel utilizing finite volume method. They also examined the case where the window temperature is lower than the room temperature.

The Trombe wall located in the moderate continental climate was numerically studied by Tamara Bajc et. al. [5] using three dimensional CFD analyses. The commercial CFD package FLUENT along with user defined functions developed using $\mathrm{C}$ programming language was utilized to carry out the analysis.

Guohoi Gan [6] carried out a study on the cooling of buildings done in passive ways. The TEAM code CFD technique based on the two dimensional finite volume method was utilized to determine the air exchange rates caused due to the passive cooling of buildings. 


\section{A. Physical Model and Coordinate System}

The physical model consists of a Trombe wall system considering both the living space and the air space [7]. The living space consists of a roof on the top side, floor on the bottom side and wall on both the sides. The left side wall is named as the interior wall while the right side of the wall is termed as exterior wall. The air space is formed by a glass placed at a distance from the interior wall. A vent is provided on the top/middle of the exterior wall and top of the glass while it is given at a very small height when measured from the floor in the interior wall which is a system utilized for the summer cooling. A two dimensional Cartesian coordinate system as shown in the above Fig 1 is utilized for representing the geometry. The direction alongside the $\mathrm{x}$ axis (right side) is taken as positive while away (left side) is taken negative. Similarly the direction alongside the y axis (vertically upwards) is considered as positive while away from the y axis (vertically downwards) is taken as negative. The unit vectors along $\mathrm{x}$ and $\mathrm{y}$ axis are taken as $\mathrm{i}$ and $\mathrm{j}$ respectively. A non-inclined domain has been considered for the analysis of the present work with the gravity vector $\mathrm{g}$ making angles $\theta \mathrm{x}=90^{\circ}$ and $\theta \mathrm{y}=180^{\circ}$. IEFHI represents the living space area while ACDJA represents the air space. The living space is made of breadth $b 3$ and height $h 1+h 2+h 3+h 4$ while the air space is made of breadth $b 1$ and height $h 1+h 2+h 3+h 4$. The roof of the air space and living space is represented by $\mathrm{CD}$ and EF while the floors are represented by AJ and $\mathrm{IH}$ respectively. The exterior wall and the glass is represented by $\mathrm{HF}$ and $\mathrm{AC}$ with $\mathrm{GF}$ and $\mathrm{BC}$ vents both having an opening size of h4 respectively. JDEIJ represents interior wall which separates the air space area and living space area having breadth $\mathrm{b} 2$ and height $\mathrm{h} 1+\mathrm{h} 3+\mathrm{h} 4$. The interior wall is having an opening KLMN as shown with a size of $\mathrm{h} 2$. The overall breadth and height of the total domain in $2 \mathrm{D}$ is $\mathrm{b}$ and $\mathrm{h}$ respectively.

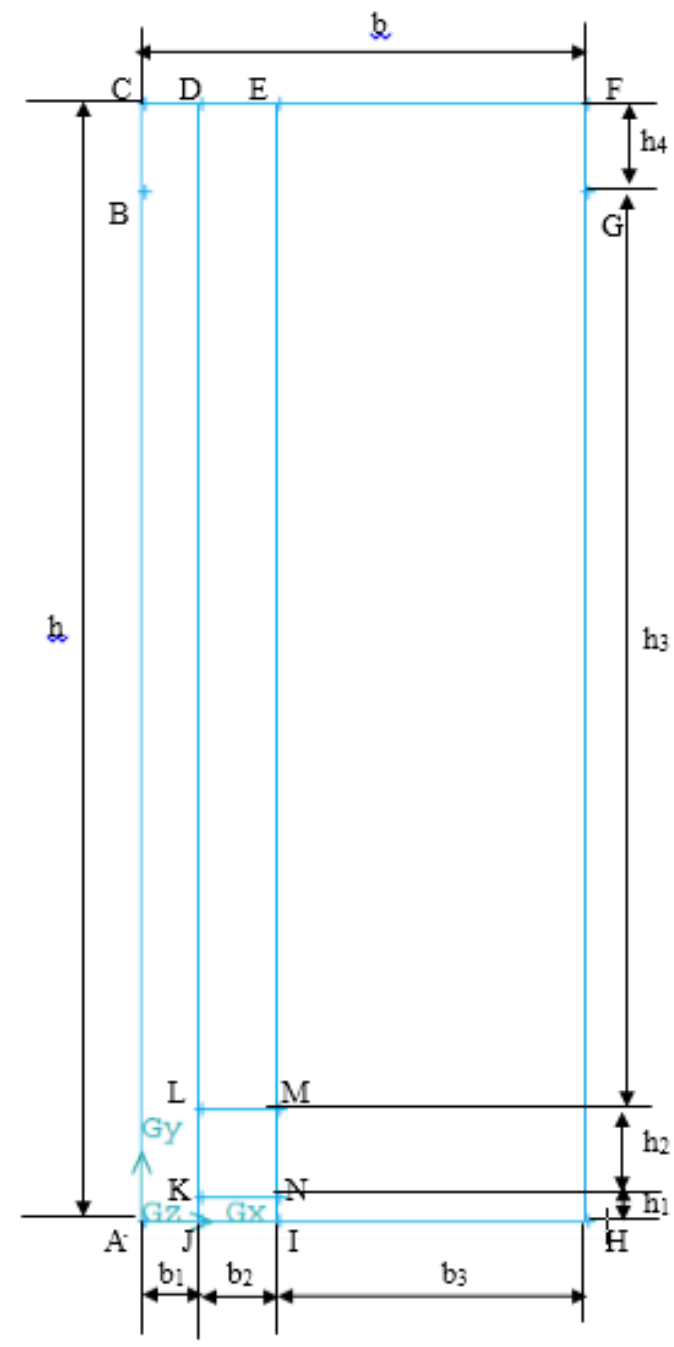

Fig. 1: Physical Model and the Coordinate System in 2D used for Passive Cooling 


\section{B. Governing Equations}

In the present problem the governing equations in the form of partial differential equations represent various parameters such as conservation of mass, momentum, energy, turbulence kinetic energy and turbulence kinetic energy dissipation rate in two dimension.

1) Continuity Equation

$$
\vec{\nabla} \cdot \vec{u}=0
$$

2) Momentum Equation

\section{3) Energy Equation}

$$
(\overrightarrow{\mathbf{u}} \cdot \vec{\nabla}) \overrightarrow{\mathbf{u}}=-\frac{1}{\rho} \vec{\nabla} \mathrm{p}+\left[\left(\gamma+\gamma_{\mathrm{t}}\right)\left(\vec{\nabla}^{2} \cdot \overrightarrow{\mathbf{u}}\right)\right]-\beta\left(\mathrm{T}-\mathrm{T}_{\mathrm{r}}\right) \overrightarrow{\mathbf{g}} \cdot \frac{\overrightarrow{\mathbf{u}}}{\frac{\overrightarrow{|\mathbf{u}|}}{\mid}}
$$

$$
\mathrm{E}(\overrightarrow{\boldsymbol{\nabla}} \cdot \overrightarrow{\boldsymbol{u}})=-[\overrightarrow{\boldsymbol{\nabla}} \cdot \overrightarrow{\boldsymbol{u}}]+\overrightarrow{\boldsymbol{\nabla}}[\mathrm{k}(\vec{\nabla} \cdot \mathrm{T})]
$$

The complete set of equations of the k- $\varepsilon$ is found in [8] and their commonly used set of parameters are obtained from [9].

\section{Boundary Conditions}

A uniform temperature throughout the domain is considered as the starting condition with the velocity along $\mathrm{x}$ and $\mathrm{y}$ directions to be zero in the air space as well as the living space. The same conditions are considered on the boundary as well as interfaces. Through the vent opening which is present in the exterior wall, the fluid enters living space at a specified temperature. The heat flux is only specified along the interior wall while a zero heat flux has been specified across the floor, exterior wall and the glass. A no slip and no permeability hydrodynamic conditions has been utilized across the walls, floor and roof while the values are specified along the vent present in the exterior wall.

\section{III.NUMERICAL FORMULATION}

Two software packages has been utilized for generating the meshed model and obtaining solution by inserting various boundary conditions that is Gambit V.2.3.16 and ANSYS Fluent V.6.3.26 respectively. A two dimensional steady state pressure based solver along with implicit formulation was used to obtain the results by the global process of iteration. The absolute velocity formulation with green gauss cell based gradient option and superficial velocity porous formulation has been used. A finite volume method of discretising the equations that will govern the fluid flow and heat transfer has been employed by Fluent to obtain the solution. A SemiImplicit Method for Pressure-Linked Equations (SIMPLE) pressure velocity coupling developed by Patankar and Spalding a guess and correct procedure has been adopted to calculate pressure on the staggered grid arrangement. In this the momentum equations are solved to obtain the velocity field initially before the pressure difference term is calculated on an initial guess from the pressure distribution. Later the latest pressure distribution is obtained from the new pressure equation formulation. Lastly the velocity is corrected and conservative fluxes are calculated. The influence of buoyancy force caused due to the difference in the densities was considered by inducting Oberbeck Boussinesq approximation model. The turbulent motion a state of agitation of air has been considered by utilizing RNG k- $€$ model with wall functions being standard was used. The default under relaxation factors were used. The default residuals of $0.001,0.001,0.001,1 \mathrm{e}-06,0.001$ and 0.001 were used for continuity, $x$-momentum, y-momentum, energy, turbulence kinetic energy and turbulence kinetic energy dissipation rate for checking the convergence of the solution. The various models that were adopted in the CFD code for some of the important parameter is shown in Table 1.

TABLE I. Settings utilized in CFD Code

\begin{tabular}{|l|l|}
\hline Parameter & Model \\
\hline Density & Boussinesq Hypothesis \\
\hline Turbulence & Standard K- $\varepsilon$ \\
\hline Energy & Activated \\
\hline
\end{tabular}

\section{A. Grid Independence Tests}

It has been concluded from the literature survey that the computational results are greatly dependent on the grid size. Hence to check whether the obtained solutions are independent of the size of the grid the tests are conducted. The grid independence tests are the process of removing the faulty results in computational fluid dynamics. The overall error could be reduced by minimizing the errors that are formed due to the grid dependence. For a particular problem once the boundary conditions and the mesh size are known, the same could be utilized in the future reducing the computational time. 
It is a well-known fact that the smaller interval size always yields larger number of cells resulting in the finer mesh. The grid independence tests are carried out for five meshes obtained from the Gambit software. The following table 2 shows the different interval size and the number of cells obtained. The tests are conducted on the summer cooling model for two different inlet temperatures of $312 \mathrm{~K}$ and $308 \mathrm{~K}$. The maximum percentage variation is found to be 0.062489 as shown in the tables 3 and 4 . Therefore it can be concluded that any of the grids mentioned can be used for analysis. The results for the present problem has been obtained with a model having 33695 cells obtained by utilizing an interval size of 0.01 as shown in the Fig 2.

TABLE 2: Number of cells generated for various interval sizs
\begin{tabular}{|l|l|}
\hline Interval size & Number of Cells \\
\hline 0.009 & 41600 \\
\hline 0.01 & 33695 \\
\hline 0.011 & 27930 \\
\hline 0.012 & 23571 \\
\hline 0.013 & 20025 \\
\hline
\end{tabular}

TABLE 3: Grid Sensitivity tests for summer cooling model with inlet temperature $312 \mathrm{~K}$

\begin{tabular}{|l|l|l|}
\hline Cells & wall temperature $\mathbf{T}_{\mathbf{w}} \mathbf{K}$ & \%difference $=\left(\mathbf{T}_{\mathbf{w}}-\mathbf{T}_{\mathbf{a v g}}\right) / \mathbf{T}_{\mathbf{a v g}} \mathbf{K}$ \\
\hline 41600 & 318.7751 & 0.05687 \\
\hline 33695 & 318.889 & 0.02116 \\
\hline 27930 & 318.9462 & 0.00323 \\
\hline 23571 & 319.0279 & 0.022385 \\
\hline 20025 & 319.1442 & 0.058848 \\
\hline & 318.9565 & \\
\hline
\end{tabular}

TABLE 4: Grid Sensitivity tests for summer cooling model with inlet temperature $308 \mathrm{~K}$

\begin{tabular}{|l|l|l|}
\hline Cells & wall temperature $\mathbf{T}_{\mathbf{w}} \mathbf{K}$ & \%difference $=\left(\mathbf{T}_{\mathbf{w}}-\mathbf{T}_{\mathbf{a v g}}\right) / \mathbf{T}_{\mathbf{a v g}} \mathbf{K}$ \\
\hline 41600 & 314.7495 & 0.05957 \\
\hline 33695 & 314.862 & 0.02385 \\
\hline 27930 & 314.9275 & 0.00305 \\
\hline 23571 & 315.0126 & 0.023973 \\
\hline 20025 & 315.1339 & $\mathbf{0 . 0 6 2 4 8 9}$ \\
\hline & 314.9371 & \\
\hline
\end{tabular}

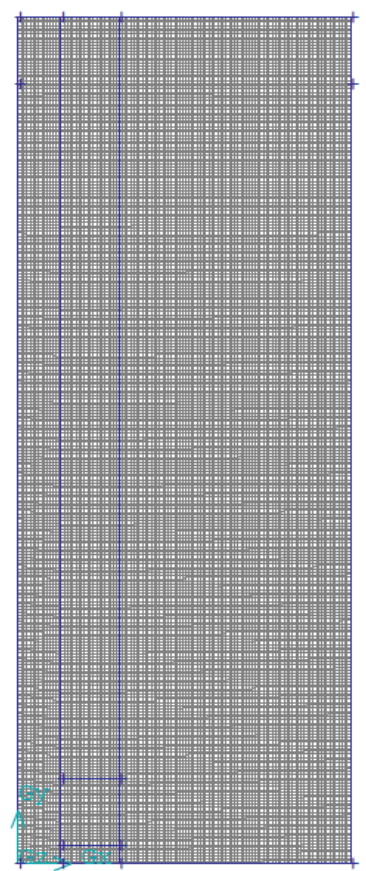

Fig. 2 Typical 2D Trombe wall for summer cooling meshed model having 33695 cells 


\section{A. Temperature Distribution}

\section{IV.RESULTS \& DISCUSSIONS}

Convection is found to be the main heat transfer mechanism. From Fig 3 when the vent is considered to be near the top of the vent it can be concluded that the temperature of the entering stream is found to prevail near the vent while it increase over the remaining region. When the vent is considered to be at the middle the temperature of the entering stream is found to prevail over the entire domain apart from the region near to the interior wall. The temperature in the living space is found to be higher when the vent arrangement is fixed at the top which can be seen in Fig 5 and 6 respectively.
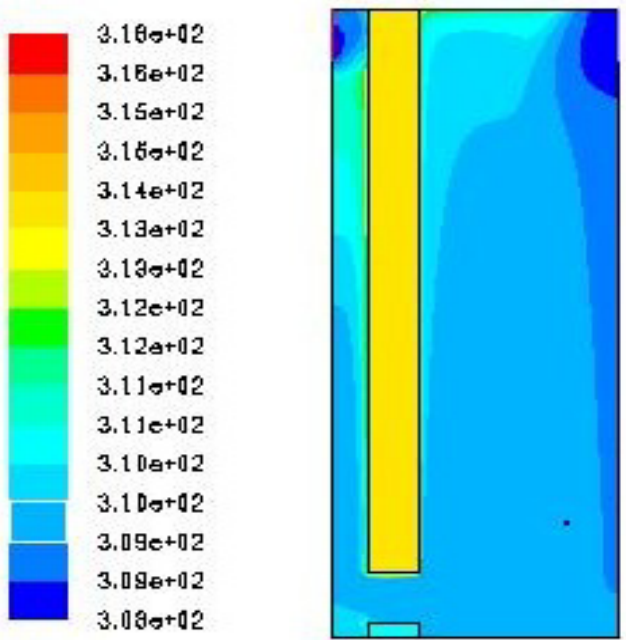

Fig. 3. Contour Plot of Static Temperature with vent at the top of the exterior wall and inlet air temperature of $308 \mathrm{~K}$
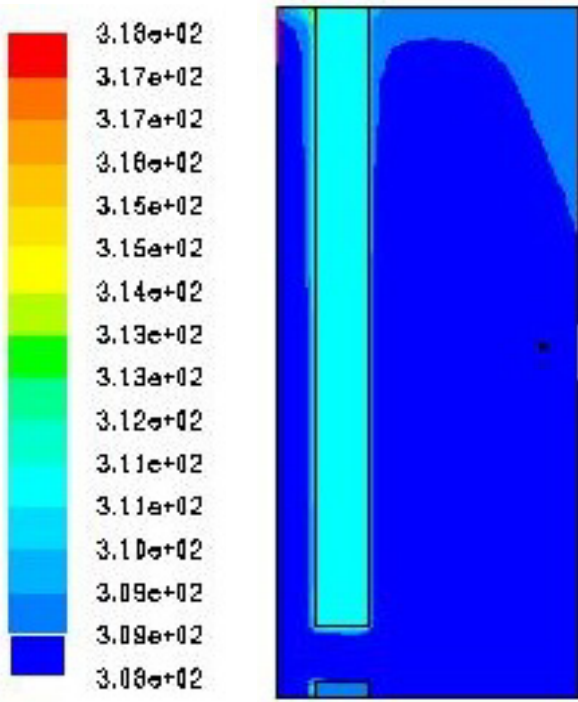

Fig. 4. Contour Plot of Static Temperature with vent at the middle of the exterior wall and inlet air temperature of $308 \mathrm{~K}$ 


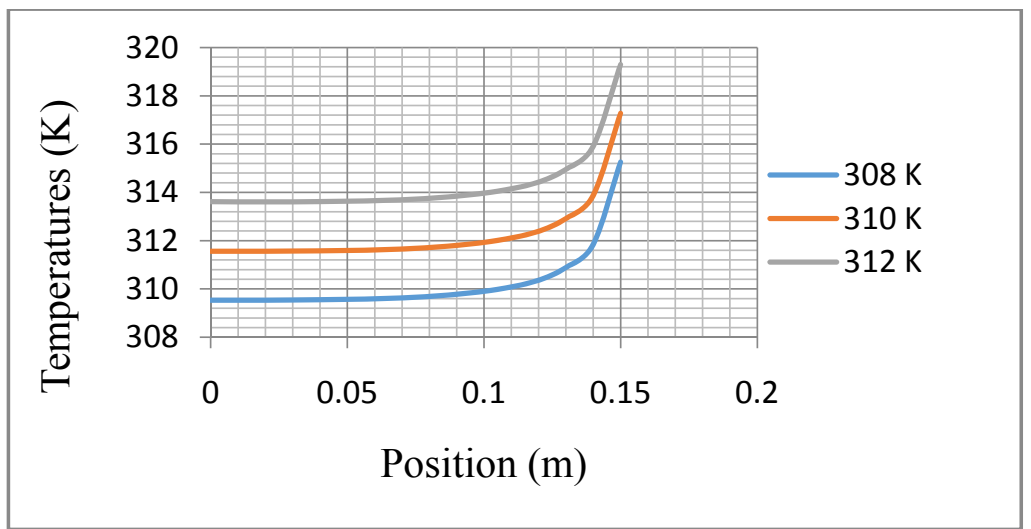

Fig. 5. Horizontal temperature distribution @ $\mathrm{x}=0$ to $0.15 \mathrm{~m}, \mathrm{y}=1.46 \mathrm{~m}$ with vent at the top of the exterior wall for various inlet air temperature

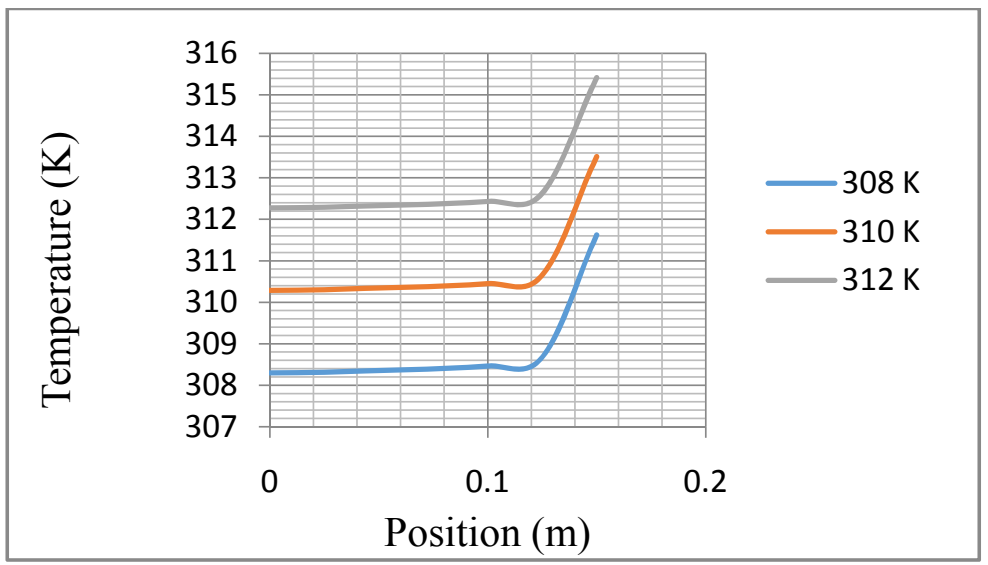

Fig. 6, Horizontal temperature distribution @ $\mathrm{x}=0$ to $0.15 \mathrm{~m}, \mathrm{y}=1.46 \mathrm{~m}$ with vent at the middle of the exterior wall for various inlet air temperatures

\section{B. Flow Field}

It can be inferred from Fig 7 and 8 a recirculation takes place in the living space. With the increase in the inlet air temperature the patterns are almost similar except that air velocities increase inside the living space.

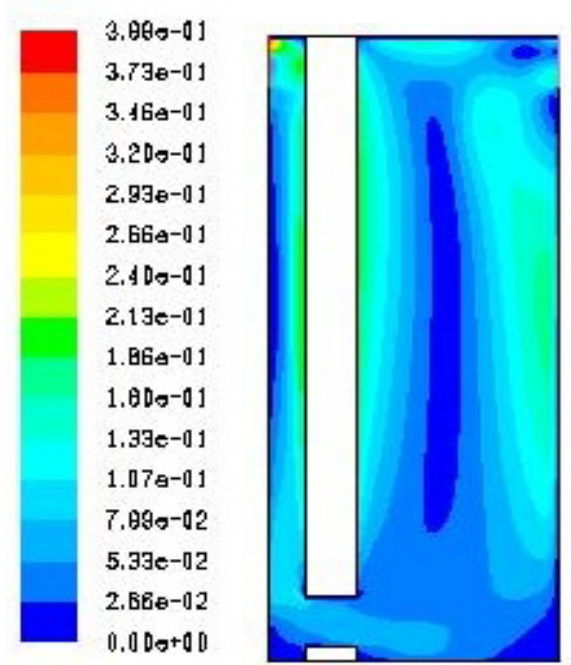

Fig. 7. Contour plot of velocity distribution with vent at the top of the exterior wall and inlet temperature $308 \mathrm{~K}$ 


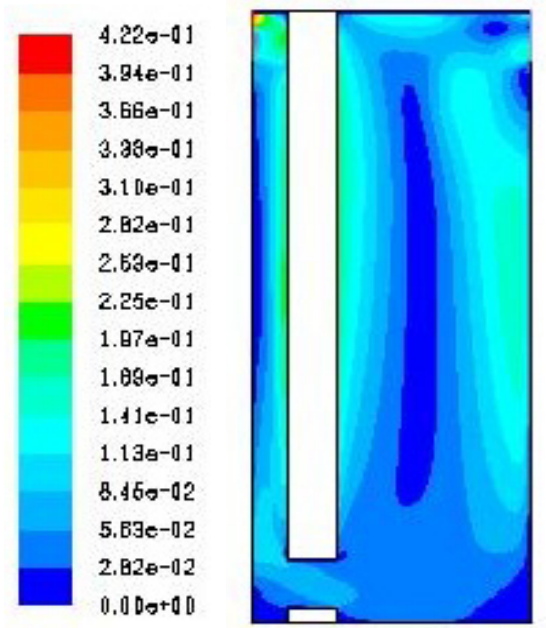

Fig. 8. Contour plot of velocity distribution with vent at the top of the exterior wall and inlet temperature $312 \mathrm{~K}$

\section{CONCLUSION}

The calculations are made using CFD code in order to determine the flow field and the distribution of temperature in a particular Trombe wall system. The following conclusions can be made from the analysis

- In the case of vent at the top of the exterior wall, the temperature in the living space area has been found to be 3-6 K greater than the inlet temperature for the different inlet temperatures considered respectively.

- In the case of vent at the middle of the exterior wall, the temperature in the living space area has been found to be 1-3 K greater than the inlet temperature for the different inlet temperatures while near to the interior wall.

- In the case of vent at the top of the exterior wall the velocity of air inside the living space has been found to be in the range of $0.025-0.169 \mathrm{~m} / \mathrm{s}$ for different inlet temperatures considered respectively.

- The vent arrangement in the middle of the exterior wall is found to be better than at the top.

\section{REFERENCES}

[1] O. Saadatian, K Sophian, C H Lim, N Asim and M. Y. Sulaiman, "Trombe walls: A review of opportunities and challenges in research and development," Renewable and Sustainable Energy Reviews, pp. 6340-6351, 2012.

[2] J. John D Anderson, Computational Fluid Dynamics: The basics with applications, New york: Mcgraw-Hill, Inc , 1995.

[3] H. K. Versteeg. \&. W. Malalaseekera, An Introduction to Computational Fluid Dynamics: The Finite Volume Method, Harlow: Longman Group, 1995.

[4] S J Ormitson, G D Raithbay and K. G. T. Hollands, "Numerical Predictions of natural convection in a Trombe wall system," International Journal Heat Mass Transfer, vol. 29, pp. 869-877, 1986.

[5] Tamara Bajc, Maja N Todorovic and J. Svorcan, "CFD analyses for passive house with Trombe wall and impact to energy demand," Energy and Buildings, Vols. xxx-xxx, p. xxx, 2014.

[6] G. Guohui, "A parametric study of Trombe walls for passive cooling of buildings," Energy and Buildings, vol. 27, pp. 37-43, 1998.

[7] R Ben Yedder and E. Bilgen, "Natural Convection and Conduction in Trombe Wall Systems," International Journal of Heat and Mass Transfer, vol. 34, no. 4/5, pp. 1237-1248, 1991.

[8] FLUENT v6.3 Manual, Lebanon, 2006.

[9] B. Mohammadi and O. Pironneau, Analysis of the k-epsilon Turbulence Model. Research in Applied Mathematics., New York, Masson, Paris: Wiley, 1994.

\section{AUTHOR PROFILE}

Bharath $\mathrm{V}$ is presently working as assistant professor in the department of Mechanical Engineering at Sri Venkateshwara College of Engineering, Bengaluru. He received M.Tech (Engineering Analysis and Design) in 2014 from SDMCET, Dharwad. His research area includes Heat Transfer, Fluid Mechanics, and Computational Fluid Dynamics.

Puneeth Kumar M V is presently working as assistant professor in the department of Mechanical Engineering at Sri Venkateshwara College of Engineering, Bengaluru. He received M.Tech (Machine Design) in 2013 from SJCIT, Chikkaballapura. His research area includes Materials and Finite Element Analysis. 